\title{
Reducing the New Inmates' Anxiety through Rational Emotive Behavior Therapy with Patronage Counseling Technique
}

\author{
Farid Junaedi ${ }^{1 *}$, Fattah Hanurawan ${ }^{1}$, Arbin Janu Setiyowati ${ }^{1}$, M. Ramli ${ }^{1}{ }_{\odot}$ \\ ${ }^{1}$ Faculty of Psychology Education, Universitas Negeri Malang, Malang, Indonesia.
}

\begin{abstract}
Recurring cases of suicide, escapement, riots, and overcapacity have been observed in correctional institutions in Indonesia. Mental health issues are one of the causes of such a phenomenon. The emergence of this mental health issue may negatively impact inmates and cause disturbances in correctional institutions. Rational Emotive Behavior Therapy (REBT) focuses on transforming an irrational concept into a rational belief. This study aims to investigate the effects of REBT counseling with patronage technique on reducing anxiety levels. This new Patron-Client platform, equipped with the signification of gratitude and contentment, becomes a new form of proper counseling in a correctional institution. This study adopted the quasi-experiment before-after method with the Solomon four-group design. To garner the data, it involved four groups divided into two experimental and two control groups, consisting of 240 research population and 160 research subjects. ANOVA and T-test analysis were used to further analyze the obtained data. The findings show significantly different anxiety levels in the inmate groups before and after the treatment. Besides, no difference was observed in the inmates who did not receive the treatment. This study concludes that REBT counseling with patronage technique significantly decreases the inmates' anxiety levels in the correctional institution.
\end{abstract}

\section{Keywords:}

Inmates; Overcapacity;

Anxiety;

Patronage Techniques;

Rational Emotive Behavior Therapy;

Correctional Institutions.

\section{Article History:}

Received: $\quad 29$ October 2021

Revised: $\quad 08$ January 2022

Accepted: $\quad 23$ January 2022

Available online: $\quad 07 \quad$ March 2022

\section{1- Introduction}

Based on the Environmental Load Theory [1], Behavioral Constraints Theory [2], Adaptation Level Theory [3], and Environmental Stress Theory [4], prisons may cause depression, obstacles in appropriate behavior, decreased adaptability, congested, and unhealthy environmental factors, increasing mental health disorders (such as paranoia, anxiety, Interpersonal Sensitivity (SI), obsessive-compulsiveness, somatization, phobias, hostility, psychotic) on the inmates. The development of correctional institutions has become one of the unresolved national problems, while the aforementioned theories suggest that inmates' mental health is essential. Considering the length of the inmates' sentences, the Correctional Institution is a new environment for them. Besides, once they come to the correctional institution, they lose their rights and obligations as normal human beings while experiencing mental disorders. Further, society's stigmatization of inmates who live in correctional institutions may affect their attitudes and perspectives [5]. Therefore, the new inmates mostly carry a negative stigma towards their fellow inmates. The data from Correctional Institution System for the last 5 years shows an increasing occupancy rate that is not followed by an increase in capacity, as presented in Table 1.

Due to the overcapacity, the prison possesses a minimum (ineffective) function, affecting the inmates' mental health, prisonization, deviant subcultures, and causing riots. The decline in mental health can also affect the new

*CONTACT: faridjunaedi88@gmail.com

DOI: http://dx.doi.org/10.28991/ESJ-2022-06-02-08

(C) 2022 by the authors. Licensee ESJ, Italy. This is an open access article under the terms and conditions of the Creative Commons Attribution (CC-BY) license (https://creativecommons.org/licenses/by/4.0/). 
inmates' suicidal tendencies. An example of the suicide case of an inmate has been reported in Lumajang Prison and a suspect of sexual immorality in Tangerang Youth Prison. Additionally, a number of riot cases have also been reported annually in the database of Indonesian Correctional Institution [6]. For example, the riots in Sragen Prison and in Lhoksukon Prison 2019. Those incidents accentuate the inmates' needs for physical, mental, and psychological health assurance [7].

Table 1. Increasing Number of Resident in Malang Correctional Institution

\begin{tabular}{|c|c|c|c|c|}
\hline Year Capacity & Throughout Indonesia & Current Occupant & Occupancy Capacity & Current Occupant in Malang \\
\hline 2016 & 130.445 & 204.550 & 936 & 2098 \\
\hline 2017 & 130.445 & 232.081 & 936 & 2419 \\
\hline 2018 & 130.445 & 255.380 & 936 & 3000 \\
\hline 2019 & 130.445 & 265.648 & 936 & 3130 \\
\hline 2020 & 130.445 & 249.139 & 936 & 3288 \\
\hline
\end{tabular}

Source: Database Systems Correctional Institution of Ministry of Law and Human Rights

The social stigma has made the new inmates encounter mental stress for an extended period since they came to the correctional institution as convicts. That high stress level and the prison situation caused the inmates to experience anxiety. Anxiety represents an emotional state characterized by physiological arousal, unpleasant tension, and fear of something terrible happening. It is defined as a feeling of worry or fear with no apparent reason [8]. Besides, Gunarsa (2008) explains that anxiety can also be a significant force in driving good behavior and deviant or disturbing behavior [9]. The initial screening process of 160 new inmates of Class 1 Correctional Institution of Malang using the Symptom Check List 90 (SCL-90) questionnaire reveals that the participants (KE-A1, KK-B1, KE-C2, and KK-D2) experience anxiety, as presented in Figure 1. The data was gathered from May to July 2019.

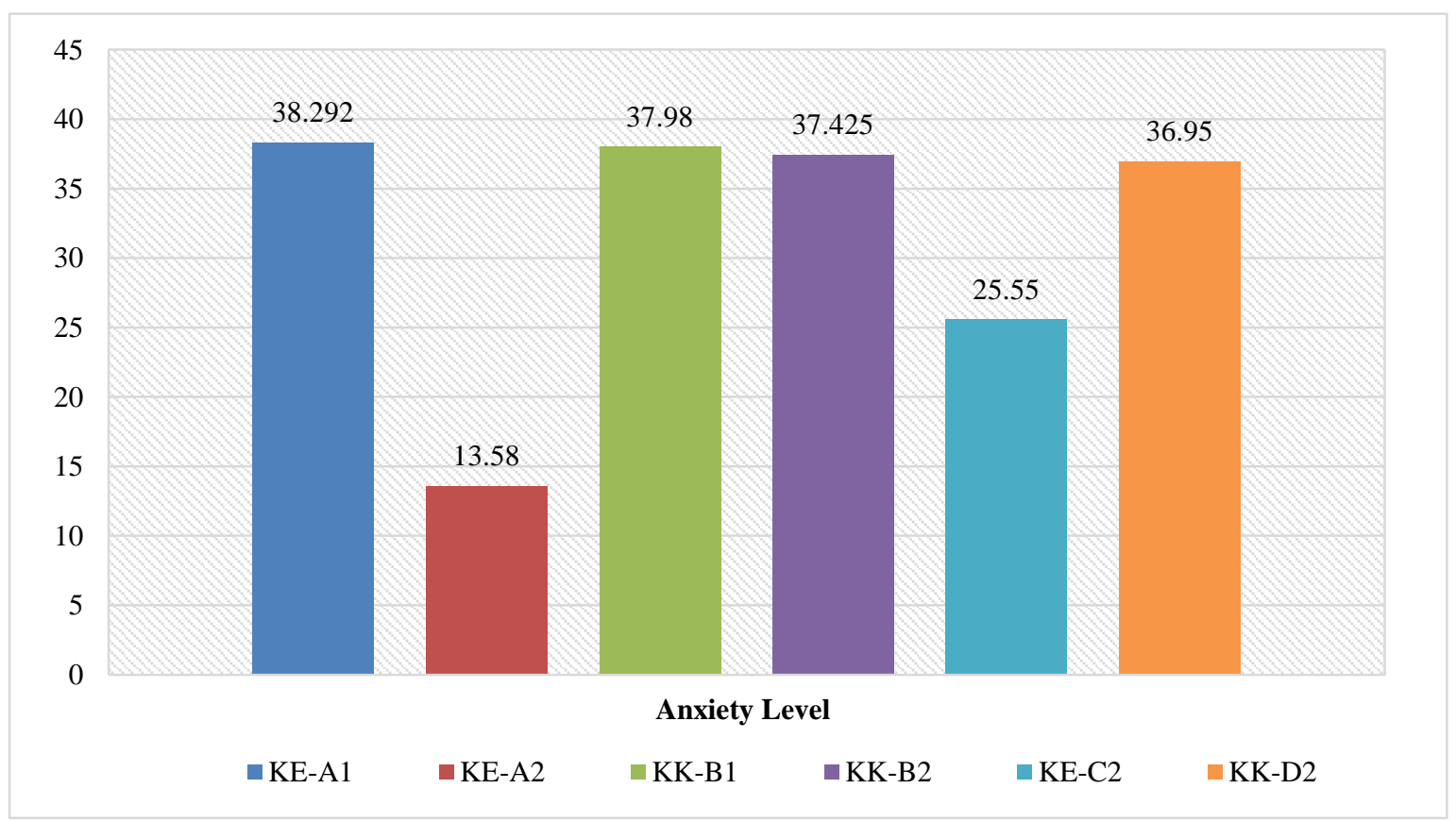

Figure 1. Description of Average $(\bar{X})$ Anxiety Levels of KE and KKX

According to Figure 1, a potentially dangerous symptom that can explode if they accumulate simultaneously has been observed. Besides, the data also confirms the presence of individual cases among the newly admitted convicts. They tend to demonstrate the symptoms of anxiety, such as dizziness, headache, itching, tense neck, strained jaw muscles, elevated blood pressure, dry mouth, faster breathing, and so forth [10]. With these symptoms, even new inmates can join riots or commit suicide.

Someone with anxiety disorder thinks irrationally. Their fear and anxiety are originated from their irrational thinking on the environment so that in minimizing the symptoms, the irrational thoughts should be adjusted. Therefore, the Therapy Rational Emotive Behavior (REB) was selected for this study. Several research results have confirmed the efficiency of the REBT theory pioneered by Albert Ellis [11-18]. Those studies report the substantial positive effect of REB in treating psychological disorders like anxiety, depression, somatization, hostility, paranoia, psychotic, and so 
forth. Similarly, REB therapy intervention has been observed to be helpful in reducing anxiety and irrational beliefs [19]. Thus, this study adopts patronage counseling techniques combined with REB theory to be applied to new inmates in overcoming their psychological disorders.

Within the cognitive behavior theory, several counseling techniques can be used to analyze a person's anxiety level reduction. One of them is the Patronage Counseling Technique. Patronage Counseling Technique is adopted from the theory Patron-Client [20, 21]. Thus, this technique is selected in this study, considering the relationship between supervisory officers and inmates in the correctional institution. This patronage counseling technique can be a new and distinct formula implemented in Class 1 Correctional Institution of Malang for Class I Lapas Prisoners Malang. It was applied to participants in the Orientation Admission Education Program (AO). This education program includes activities of observation, introduction, and environmental research (Mapenaling) for one month, aiming to reduce new inmates' mental or psychiatric disorders, with the symptoms of somatization, obsessive-compulsive, interpersonal sensitivity, depression, anxiety, and psychotic.

Furthermore, most of the correctional institutions implement the proper correctional system principles manifested in the expression of Grija Winaja Djanma Miwarga Laksa Dharmesti as stated in Government Regulation No. 32 of 1999 (Governmental Law No. 32/1999) and amended into PP. 99/2012 concerning Guidance and Guidance of Correctional Inmates (hereinafter referred to as WBP). The Grija Winaja Djanma Miwarga Laksa Dharmesti emphasizes that the education process always involves mentoring activities because education is "a conscious and planned effort to create a learning atmosphere and learning process so that students actively develop their potential to have religious-spiritual strength, self-control, personality, intelligence, noble character, and skills needed by himself, society, and the nation" (Law Number 20 of 2003 concerning the National Education System Article 1 Paragraph (1)). In comparison, education helps human development or humanizes humans. Thus, education helps humans perfect themselves as human beings.

During the coaching process, the educational activities in the correctional institution mostly include counseling activities. This counseling process is provided since inmates are involved in various problems caused by their case or verdict, the influence of stigma and the prison environment (there is overcapacity and encounters with a new culture), as well as their personal problems, such as their own families and so forth Considering the absence of standardized counseling model or technique and concrete program of reintegration or orientation for new inmates in all correctional institution in Indonesia, this study seeks to develop a gradual and continuous guidance program for new inmates. However, the REBT treatment with patronage technique has not been investigated and implemented in a correctional institution. Thus, this study investigates the efficiency of rational emotive behavior therapy with patronage counseling technique in reducing the new inmates' anxiety level in Class 1 Correctional Institution of Malang. The efficiency was examined through an experiment on the new inmates who were asked to attend the counseling with patronage technique for four to five weeks. The final results were compared to the control group, who had not attained any treatment.

\section{2- Theoretical Background}

\section{2-1- Theory of Anxiety}

The term anxiety refers to excessive distress in response to a looming real or imaginative danger that has not occurred [22]. Kaplan et al. (1995) describe anxiety as a normal response to certain threatening situations and the developments, changes of new or unprecedented experiences during the process of finding self-identity and meaning in life [23]. Anxiety can be experienced by anyone. However, excessive anxiety, especially anxiety disorder, hinders the function of someones' life. Meanwhile, Nevid et al. (2011) define anxiety as an emotional state characterized by troublesome tension, physiological provocation, and concern that something terrible will happen [12]. In general, anxiety is a physiological or psychological circumstance with a wide behavioral, cognitive, somatic manifestations, and emotional, spectru, that produce discomfort, panic, and nervousness [24]. Hall (1954) describes anxiety as a distressing emotional experience produced by stimulation of the body's internal organs [25]. Therefore, anxiety is an emotional reaction that could be experienced by everyone in the form of fear, tension, or anxiety that comes from danger or threat, or other unidentified or unrecognized sources. Thus anxiety is a term used to describe the usual feelings that people experience when faced with threats, danger, or when stressed.

Studies have confirmed that every human being may experience stress [26], primarily for the inmates. New inmates mostly have a high level of anxiety and negative thoughts circulating on their future life as ex-inmates, including the possibility of the hardship to get future employment [27]. Besides, their worse fear of getting no job in the future aggravates their anxiety level [28].

Behaviorists view fear as a reflected reaction to events that trigger fear. Besides, they interpret anxiety as a response to the frustrating real-life consequences. They believe that anxiety appears when fear coexists with practically different objects or events and is incorrectly associated with them. Consequently, techniques of behavioral therapy focus on 
emotional distress symptoms. Emotional problems are perceived as a consequence of incorrectly acquired patterns of behavior or inability to learn effective responses to their environment. Behavior therapy's aim, also known as behavior modification, is to change behavior patterns. One prominent behavioral technique, systematic desensitization or conditioning, was invented by the behaviorist [29]. This therapy was first used to teach muscle relaxation to someone who was afraid of tarantula, which is incompatible with anxiety. After several days of practice, the patient and the therapist go through the suggested scenarios, one step at a time, ensuring the patient remains relaxed, backing away if necessary, until the person can finally remain tension free while he imagine the tarantula [30]. The exposure of feared objects gradually increased, while the patient learned to control their reactions. Relaxation training is frequently done concurrently to further reduce anxiety.

In addition, the cognitive theory believes that a mere problematic situation does not result in anxiety. In contrast, they think that individual interpretations cause anxiety, while the anxiety is unrelated to the outside world. A person may misinterpret real situations, which will cause unreal anxiety [31]. Anxiety disorders arise from repeated perceptions of the world as a dangerous place in ways that induce habitual maladaptive interactions into cognitive, behavioral, and physiological response systems. From a cognitive-behavioral standpoint, researchers have discovered a clear relationship between psychopathology and cognitive processes [32]. This view uses a cognitive approach to diagnose and treat psychopathology such as social phobia and emphasizes the effects of non-functional cognition on the disorder. Individuals suffering from social anxiety frequently focus on their shortcomings in social performance, increasing their anxiety symptoms [33]. Besides, another factor that affects the inmates' anxiety is their emotional readiness to get proper psychological treatment. It may be induced by the minimum communication, separation from their family, and their unstable residency [34].

The criteria that reflect the occurrence of anxiety are a) having excessive worry about several events or activities; b) having difficulty controlling worries; c) having significant difficulty or impairment in occupational, social, or other important areas of functioning; and d) experiencing at least three bouts of agitation or locked up, getting tired quickly, having trouble concentrating, being irritable, experiencing muscle tension, or having trouble sleeping (DSM-IV-APA, 1994) [35]. Anxiety disorders have an impact on how a person thinks, feels, and behaves and, if left untreated, can cause considerable stress and disruption in that person's life. Furthermore, Hunt (1999) distinguishes anxiety from fear by describing anxiety as a psychological state of high sensitivity to some perceived threat, risk, danger, or the experienced crisis [36]. Psychologically, fear is a natural response to danger. This suggests that the distinction between current danger versus future harm distinguishes fear from anxiety.

The anxiety level can be measured by detecting the symptoms experienced by someone. It is carried out using a detection tool that measures the symptoms in an individual. Therefore, to obtain data on anxiety syndromes, proper measuring tools, perseverance, and foresight, and the honesty of people who measure is required. Many psychiatrists and psychologists use anxiety measuring tools as a tool to measure the anxiety of a person or client, one of which is the Hamilton Anxiety Rating Scale (HARS), Visual Analog Scale for Anxiety (VAS-A), The Test of Anxiety Inventory (TAI) and so forth. This study used the Symptom Check List-90 (SCL-90) measuring instrument, considering that the research site (Class 1 correctional institution of Malang) uses SCL-90 as a measurement of anxiety. This measurement can be used by anyone (prison officials) since it provides simple questions and uses a checklist so that the inmates can do it themselves). The Symptom Check List is a self-report questionnaire that is used to identify behavioral symptoms of psychiatric outpatients. It was originally designed for drug trials to compare the efficacy of various. Since that moment, it was used as a measure of symptom severity, psychiatric case-finding instrument, and as a descriptive measure of psychopathology in different patient populations. The SCL-90 is designed to assess symptom severity on nine different subscales. Ninety items on the questionnaire are rated on a 5-point Likert scale, indicating the degree of symptoms occurrence. This SCL-90 usually takes between 12 to 20 minutes to complete. It is a 90-item self-report questionnaire designed to reflect the psychological symptom patterns of psychiatric and medical patients. It measures the current symptom status, not the personality of the patient. Each item of the questionnaire is rated by the patient on a five-point scale from 0 (not at all) to 4 (very often). SCL-90 consists of 9 main symptom, namely 1) somatization (SOM, 12 items), 2) obsessive-compulsive disorder (OC, 10 items), 3) interpersonal sensitivity (INS, 9 items), 4) depression (DEP, 13 items), 5) anxiety (ANX, 10 items), 6) hostility (HOS, 6 items), 7) phobias (PHO, 7 items), 8) paranoid idea (PAR, 6 items) and 9 ) psychoticism (PSY, 10 points).

\section{2-2- Theory of Rational Emotive Behaviour Therapy}

According to the Psychology Today website [37], REBT is defined as "... a short-term form of psychotherapy that helps you identify self-defeating thoughts and feelings, challenge the rationality of those feelings, and replace them with healthier, more productive beliefs. REBT focuses primarily on the present moment to assist you in understanding how unhealthy thoughts and ideas cause emotional distress, which leads to harmful actions and behaviors that interfere with your current life goals. Negative thoughts and actions can be changed and replaced with more positive and productive behavior once identified and understood, allowing you to develop more successful personal and professional relationships." Thus, REBT is a form of short-term psychotherapy that find self-defeating feelings and 
thoughts, challenge the irrationality of these feelings, and replace them with rational beliefs that are healthier and more productive. Its purpose is to resolve emotional and behavioral problems and disorders and to assist people in living happier and more fulfilling lives [38, 39]. Ellis, first presenting his ideas at the American Psychological Association conference in 1956, then published an article in 1957 entitled Rational Psychology and Individual Psychology [40]. During that time, he laid the groundwork for Rational Therapy and patiently answered questions from Rudolf Dreikurs and others about the similarities and differences between Alfred Adler's individual psychology and Rational Therapy [41]. Ellis' approach changed its name to Rational Emotive Therapy in 1959, then currently it is named Rational Emotive Behavior Therapy (REBT) since 1992 [39].

REBT perceives that humans have tendencies and innate rationale (self-help, socially helpful, and constructive) and irrational (self-defeating, socially defeating, and unhelpful). REB therapy claims that people unconsciously and consciously construct emotional difficulties such as self-blame, clinical anger, self-pity, hurt feelings, guilt, depression, anxiety, shame, and behavioral tendencies such as procrastination, compulsions, avoidance, addiction and withdrawal through their irrational and self-defeating thoughts, emotions, and behaviors [42]. Ellis (1993) also stated that some of the basic assumptions of REB therapy can be referred to as postulates, including a) thoughts, feelings, and behavior that continuously interact and influence each other; $b$ ) emotional disturbances caused by biological and environmental factors; c) influences from other people, the surrounding environment, and individuals who intentionally affect people around them, and d) self-hurt cognitively, emotionally, and behaviorally [43]. The difficulty to adapt to new environment may induce aggressive behavior that harm other people [44, 45].

According to Ellis (in George \& Cristiani, 1990), the general goal of REB therapy is to help clients minimize emotional disturbances, reduce self-defeating behaviors, and help them to be more self-actualized so that they can lead a happy life [46]. Meanwhile, Corey (2011), the general goal of REB therapy is to teach clients how to separate their behavioral evaluation from self-evaluation - its essence and totality-and how to accept it with all its shortcomings [47].

The propensity to think rationally and irrationally is one of human characteristics. REBT is also a directive approach, an approach that helps the counselee to re-learns the cognitive inputs that cause an emotional disturbance. Its goal is to persuade the counselee to accept his emotional thoughts or learn to anticipate the benefits or consequences of behavior. This is also encountered by inmates who do not accept their existence in prison. The inmates also tend to have irrational thoughts, which can then influence their behavior. Thus, REBT is expected to change irrational thinking that can affect the inmates' emotions and behavior.

Along with REB Therapy, Ellis also developed the ABC Theory of Personality. In this theory, significant activating events (a) cause humans to create masturbatory belief systems of rigid thoughts, views, beliefs about how they, other people, and the world should and should be in a state that is by their wishes; (b) which leads to emotional consequences and (c) following their beliefs. According to ABC personality theory, the emotional consequences (C) that follow a particular activating event (A) are primarily created by the individual's belief system (B) rather than the activating event itself. For example, if someone experience grief (C) from receiving sadistic treatment in cell (A) due to the belief of "I am a bad prisoner" (B) rather than the evaluation itself. Therefore, by a rational and behavioral discussion on the emotional consequences, the emotional disturbances are minimized and greatly reduced. Ellis elaborates his theory by suggesting that complex thought and emotion are more likely to be disturbed when based explicitly on a masturbatory belief system consisting of absolute necessity (such as " I really need to be liked by everyone. "). As a result, acknowledging and controlling the absolute imperative of masturbatory belief systems is likely to reduce emotional distress. Regardless, Ellis firmly believes that individual should take responsibility for his or her behavior.

\section{2-3- Patronage Counselling Techniques}

Counseling guidance is an integral part that cannot be separated from the process of inmates' coaching or education, so it is equally important as leadership, administration, supervision, and the instructional process of the learning in correctional institutions. Therefore, the inmates' counseling is a systematic, logical, continuous, and programmed effort carried out by counselors or prison officers who are trained in counseling to facilitate the development of inmates or counselees so that they can achieve independence in their lives in prison and subsequently become better individual once they are released in the community. This counseling focuses on individuals to think, decide, judge, act and analyze. The new inmates change their initially irrational and illogical way of thinking into something logical and rational by confronting, opposing, attacking, discussing, and questioning irrational beliefs so that prisoners will become productive, happy, and better. As stated by Hanurawan (2015), solving the human problem means facilitating humans to achieve the ultimate goal of human life, to be welfare or happy [48].

In general, clients and counselors who do counseling have an equal relationship. However, it is undeniable that these conditions are difficult to achieve in certain situations, such as the relationship between superiors and subordinates in the workplace, between kyai (religious figure) with the students (effects of Indonesian culture and 
norm). A similar situation also occurs in correctional institutions, between the officers and inmates. During a challenging situation, an inmate can only seek help from God, the correctional officer, and himself. Influence or help from family, relatives, and closest friends is doubtful because their interactions are limited. If he can no longer solve his problem, then the inmate can as help from the officer. This condition eventually led to the inmates' dependence on the officers. It is undeniable that the degree of inequality between the inmates and the officers affects the inmates' psychological condition. The new inmates will automatically feel under the person who influences them. However, the counseling can still be carried out. However, a different counseling technique from general counseling is required, such as the patronage counseling technique. Patronage counseling technique is a counseling model adopted from the Patron-Client theory, explaining a special relationship between the patron and the client, in the form of instrumental friendship, in which the patron has more power, authority, and status than the client [20, 21]. A similar relationship is also observed between the supervisory officer in prison and the inmate in the context of each party's responsibilities, duties, and obligations. Patronage technique is an attribute given to counseling program through specific means for the new inmates experiencing anxiety syndromes. It uses a patron-client platform in which the counselee has lower position (inferior) and the patron has higher position (superior), facilitating the inmates to resolve their own issues. It is characterized by the presence of: a) inequality; b) face-to-face meetings; and c) diffuse flexibility. The procedures in the Patronage Counseling technique are:

- Cooperating with the counselee (engage with a client);

- Conduct an assessment of the problem, person, and situation (assessment of the problem, person, and situation);

- Prepare the client for therapy (prepare the client for therapy) by referring to the patronage counseling guidelines (understanding on meaning of live, gratitude, and happiness);

- Implement the treatment program (implement the treatment program);

- Evaluate the progress;

- Prepare the counselee to end counseling (prepare the client for termination) with the attained target in client behavior changes in daily life or the emergence of appropriate behavior, along with a greater understanding of future life.

The term patronage is originated from the Patron-Client theory Scott, (1994), which explains that in social interaction, each actor has a reciprocal relationship [20]. This occurs vertically (one actor has a higher position) or horizontally (each actor has the same place). The word "patron" is from Spanish, which means someone with power, status, authority, and influence. Meanwhile, the client is someone whose position is under the patron, namely a subordinate who can be ordered [49]. The patron-client relationship is a two-way street between the two roles which can be expressed as a particular case of a bond involving instrumental friendship in which a person of higher socioeconomic status (patron) uses his influence and resources to protect and benefit someone of lower socioeconomic status (client). For the true client, the primary goal of the Patron-Client relationship is to provide basic social security for subsistence and safety. Assume the transactional relationship that serves as the foundation for these patron-client relationships deteriorates because it no longer provides basic social security for subsistence and security. In that case, the client will consider this relationship to be unfair and exploitative. Once that occurs, the relation becomes a mere legitimacy with no linear function of a balance of transactions. Therefore, it is common if the client demands his patron to fulfill his promises or basic needs in accordance with his role and function, even though, structural, the position of the inmate is weaker. The relationship is not transactional but tends to be imperative. Comparably, the patron does not have professional standards as a counselor but carries out and practices the role as a counselor. Patronage counseling is a new formula for prison officers to use with inmates. This technique emphasizes the element of the meaning of happiness conveyed to prisoners who are experiencing difficulties as they progress through the stages of incarceration:

- In the correctional institution, prisoners interact with the prison officers appointed as the correctional guardian, whose job is to help the prisoners improve their life. Therefore, the correctional guardian's relationship with the inmates must be strong because this guardian will be the first person to assist the inmates.

- Every human being is unpredictable, and sometimes they encounter a huge problem that must be accepted and perceived as a God-given blessing, as well as solved in a flexible manner.

- The presence of collaborative gratitude and mature self-evaluation or introspection (belief by looking at selfability/self-reality).

- The rapid progress of the times and more transparent reporting help everyone to access trustworthy news.

- Undergone the test and trials using sufficient mental or spiritual capability, sincerity in accepting their destiny and sharing their experience with others to live their life comfortably. 
- They should live their life flexibly to avoid a tense and egocentric personality (be a flexible individual).

- They should understand that humans always have flaws and have made mistakes. Without mistakes, it is impossible to be a successful and happy human being.

- Socializing and mingling (understanding the public interest, laws, and regulations) requires adequate moral ethics.

- Maintaining a conscious mind, especially in this chaotic world.

Those essential happiness elements were conveyed to each inmate who has problems, along with the rational emotive behavior therapy counseling model to cultivate positive in dealing with problems that come from inside and outside prisons (family, siblings, friends, and so forth).

\section{3- Research Methodology}

This quasi-experiment investigates the effect of REB therapy through the patronage counseling technique on the new inmates divided into the experiment and control group. Meanwhile. The Solomon Four-Group Design with a before-after pattern was adopted as the research design. Consequently, this study involved two control and two experiment groups, which consisted of 160 inmates in total. Thus, each group had 40 inmates. The research subjects were selected randomly from 80-90 inmates who have to attend the orientation admission program each month. All of the selected participants have at least one year of sentence. The same stages to choose the research participant were repeated until 160 participants were gathered. The adopted quasi-experiment design is illustrated in Figure 2.

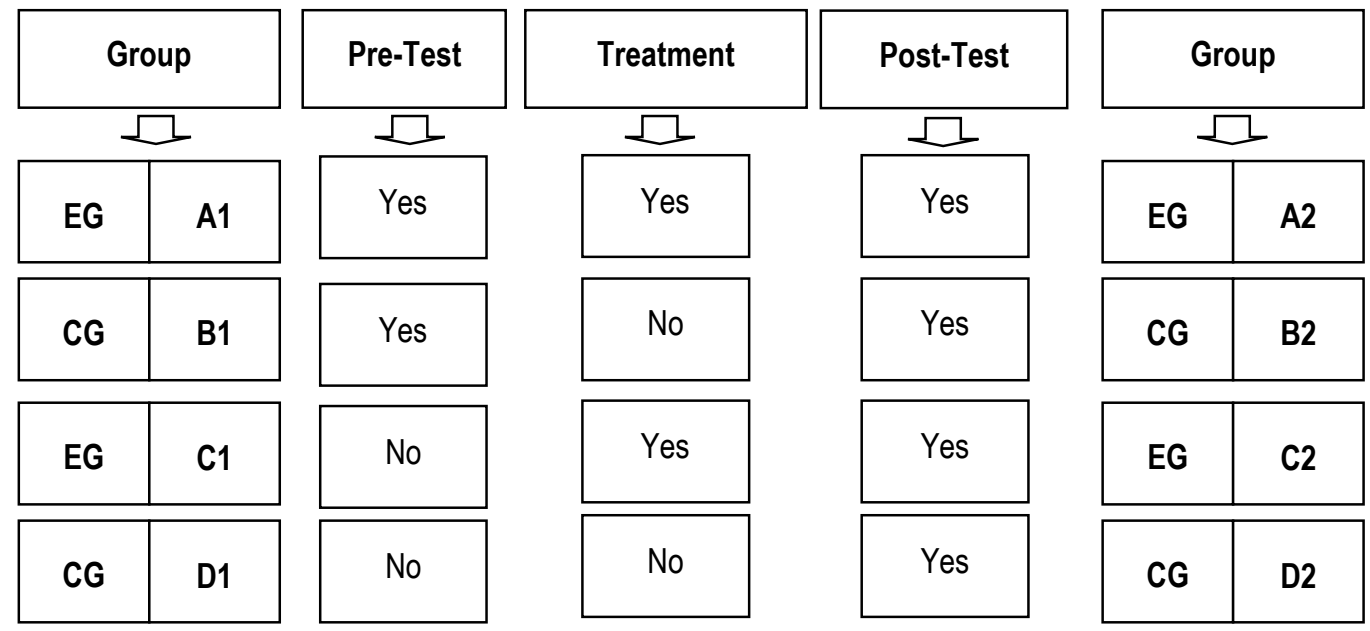

Figure 2. Quasi-Experimental Design of REBT with Patronage Counselling

According to Figure 3, two experiment groups (EG) (consisting of 40 inmates each) were coded A1 (for the observation 1) and $\mathrm{C} 1$ (without observation), while the two control groups (CG) (consisting of 40 inmates each) were coded B1 (for observation 3) and D1 (without observation). Group A1 had undergone a pretest using SCL-90, while the results of their observations were recorded. After that, they were given REB therapy through Patronage counseling for four weeks and then retested, and the results were recorded ( $\mathrm{A} 2=$ observation 2$)$. The results of those two tests were compared. Meanwhile, groups B1 and B2 as control groups were also treated with pretest (observation 3) and post-test (observation 4) but were not treated with REB therapy. The test results between the B1 (observation 3) and B2 (observation 4), A1 (observation 1), and B1 (observation 3), as well as A2 (observation 2) and B2 (observation 4) were compared.

Meanwhile, group $\mathrm{C} 1$ as the experiment group was not given a pretest (without observation) but was given REB therapy through Patronage counseling for four weeks, followed by a post-treatment test (as of observation 5). The results were recorded as C2 (observation 5), which were compared with the results of A2 (observation 2), B2 (observation 4), and D2 (observation 6). Furthermore, the D1 group as the control group was not given the initial test (without observation) and also not given REB therapy, but after the inmates got into the correctional institution for four weeks, they were given a test, and the results were coded D2 (observation 6). Thus, the measurement results were coded with a "yes" code both from the pretest and post-test. In the end, there were four groups (A, B, C, and D) and six kinds of measurement results or observations (A1, A2, B1, B2, C2, and D2), which were analyzed for the significance of the differences. 
The Symptom Checklist 90 (SCL-90) instrument was adopted in this study as the screening measurement on the new inmates' mental health. Initially, the instrument had been adapted, while its validity and reliability were also tested. The instrument's reliability test results show the $r_{a}=0.930$ coefficients, classified as reliable. Meanwhile, the instrument's item validity test shows that each item's coefficient ranges from $0.607-0.929$, categorized as valid. The instrument was used to obtain data on the new inmates' anxiety during the admission orientation program divided into experimental groups coded with A1 and control groups coded with B1. Meanwhile, after the admission orientation program and the experiment process, the data were coded with EG-A2 and CG-B2 (with no intervention) and EG-C2 and CG-D2 (with no intervention).

The obtained data were analyzed using one-way analysis of variance (ANOVA) or t-test through the SPSS program for windows. The analysis could be carried out simultaneously (multivariate analysis) or omnibus to identify the effects of REB therapy on the new inmates' difference anxiety levels (between the control and experiment groups). In addition to the ANOVA technique, a t-test was also adopted. Suppose the $\mathrm{H}_{0}$ was rejected $(\mathrm{P}<\alpha 0.05)$, then the average significant difference was investigated to reveal which pair carry substantial differences. However, if the ANOVA results accept the $\mathrm{H}_{0}(\mathrm{P}>\alpha 0.05)$, then the t-test was not carried out.

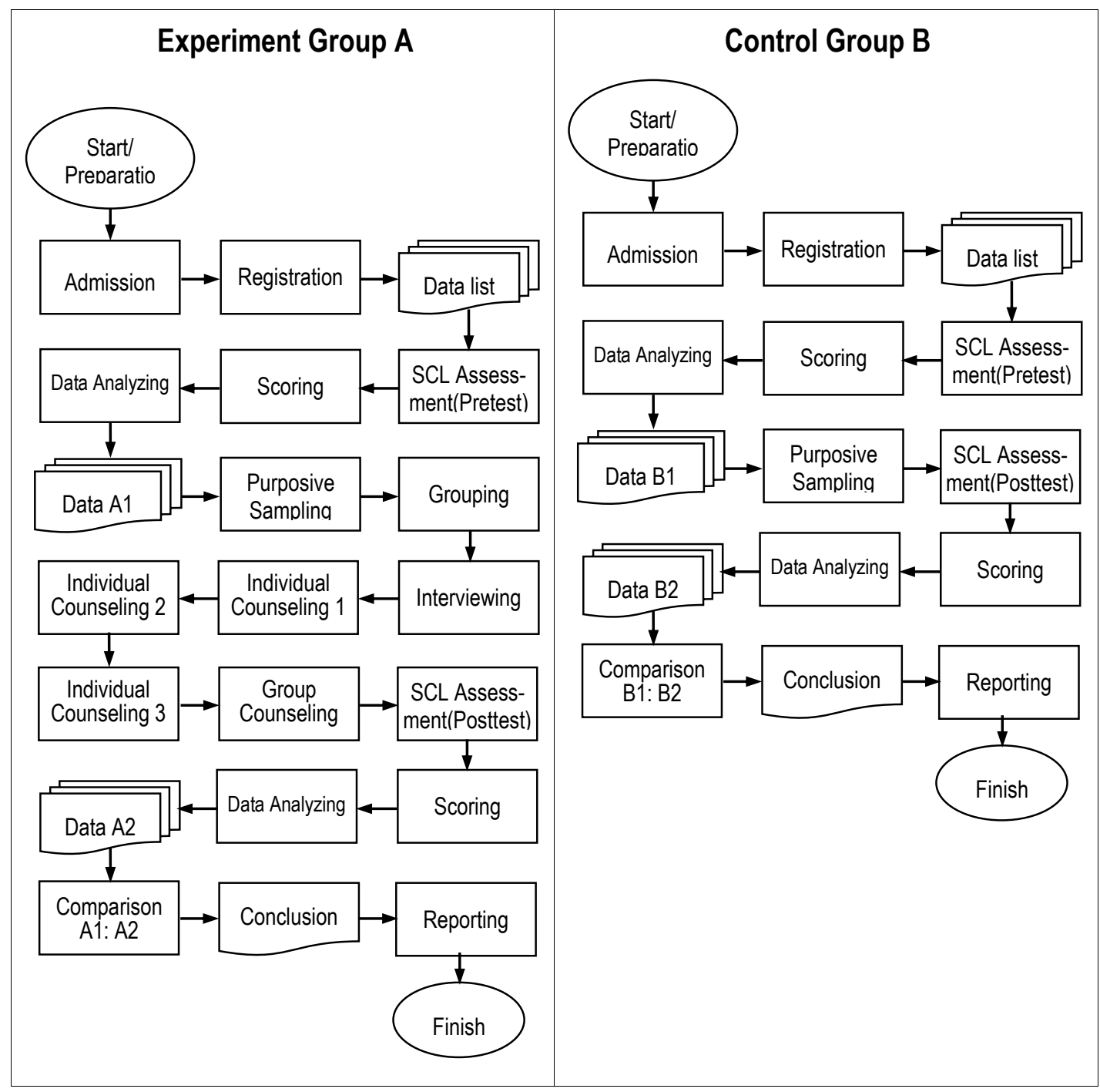

Figure 3. Stages of Research Method

\section{4- Results and Discussion}

The results of data analysis subsist of research participants' descriptions divided into experimental groups (EG) and the control group (CG). The first EG is coded with number 1 as pre-therapy observation and number 2 as post-therapy observation. Meanwhile, EG with C codification shows the second EG along with the same code of observation. The Control Group (CG) also has two groups, with code B and D, along with the notation numbers 1 (pretherapy) and 2 (posttherapy).

The description consists of the average $(\bar{X})$ Anxiety Levels of the new inmates and frequency tabulation based on their characteristics. It also presents the results of testing the research assumptions (as a requirement for analysis), the 
results of the research hypothesis testing. The data were divided into two categories, the first and second. The first data consists of data obtained from the process of observing the EG (A1, A2, and C2), and the second is data obtained from observations of CG (B1, B2, and D2). Each type of group consisted of 40 cases $(n=40)$, so the total number of observations is 240 cases $(N=240)$ on the new inmates' level of anxiety.

In addition, the second data subsists of the new inmates' level of anxiety obtained from the first observation without the data from the repeated observations. The collected data are from the observations of EG-A1, CG-B1, EG-C2, and CG-D2. Each group consists of 40 people, so the total number for this second data category is (N) 160 cases.

\section{4-1- Results of Observation}

\section{a. Distribution of $\bar{X}$ Anxiety Levels in the Experimental Group (EG) and Control Group (CG)}

Table 2 shows the anxiety level of EG-A1 (pre-screening) is 38.292 , which is similar to CG-B1 $=37.975$ (prescreening), CG-B2 $=37.425$ (post-screening), and CG-D2 $=36.950$ (post-screening). However, the post-screening data presents great difference of anxiety level in the four groups between EG-A2 and EG-A1 (13.575 - 38.292 = -24.717); between EG-A2 and CG-B1 (13.575 - $37.975=-24.400)$; between EG-A2 and CG-B2 (13.575 - $37.425=-23.850)$; and between EG-A2 and CG-D2 $(13.575-36.950=-23.375)$. In contrast, the anxiety level difference between EG-A2 and EG-C2 is relatively small $(13.575-25.550=-11.975)$. It signifies a relatively low level of anxiety in EG. Therefore, a further examination on the level of difference is required to see if it is resulted from the Rational Emotive Behavior (REB) therapy using previous Patronage Counseling.

Table 2. Summary of Anxiety Variable's Descriptive Analysis on the EG and CG

\begin{tabular}{ccccccc}
\hline Parameter Observation & EG-A1 & EG-A2 & CG-B1 & CG-B2 & EG-C2 & CG-D2 \\
\hline Mean $(\bar{X})$ & 38.292 & 13.575 & 37.975 & 37.425 & 25.550 & 36.950 \\
Standard Deviation & 2.651 & 2.205 & 2.224 & 1.920 & 2.218 & 2.385 \\
Variant & 7.026 & 4.866 & 4.948 & 3.687 & 4.921 & 5.690 \\
Skewness & -0.209 & 0.453 & -0.305 & -0.417 & -0.063 & -0.475 \\
z Skewness & -0.540 & 1.170 & -0.788 & 1.077 & -0.163 & -1.226 \\
Kurtosis & -0.520 & -0.325 & 0.126 & -0.948 & -0.662 & -0.261 \\
z Kurtosis & -0.671 & -0.420 & 0.163 & -1.225 & -0.855 & -0.337 \\
Distribution & Normal & Normal & Normal & Normal & Normal & Normal \\
Min Score & 32.123 & 10.293 & 32.214 & 31.187 & 21.324 & 31.278 \\
Max Score & 43.321 & 19.371 & 42.198 & 40.342 & 30.197 & 41.312 \\
Span & 11.198 & 9.078 & 9.984 & 9.155 & 8.873 & 10.034 \\
Sum & 1518.022 & 543.143 & 1519.211 & 1485.301 & 1455.072 & 1478.241 \\
N (observation) & 40 & 40 & 40 & 40 & 40 & 40 \\
Min Possibility & 10.000 & 10.000 & 10.000 & 10.000 & 10.000 & 10.000 \\
Max Possibility & 49.807 & 49.807 & 49.807 & 49.807 & 49.807 & 49.807 \\
\hline \multicolumn{1}{c}{ Data assumptions testing for the } & Analysis of Variances $($ Anova $)$ & \\
\hline Span Possibility & 39.807 & 39.807 & 39.807 & 39.807 & 39.807 & 39.807 \\
Interval & 9.950 & 9.950 & 9.950 & 9.950 & 9.950 & 9.950 \\
Normal Category & $<19.951$ & $<19.951$ & $<19.951$ & $<19.951$ & $<19.951$ & $<19.951$ \\
Low Category & $<29.902$ & $<29.902$ & $<29.902$ & $<29.902$ & $<29.902$ & $<29.902$ \\
High Category & $<39.852$ & $<39.852$ & $<39.852$ & $<39.852$ & $<39.852$ & $<39.852$ \\
Very High Category & $>39.852$ & $>39.852$ & $>39.852$ & $>39.852$ & $>39.852$ & $>39.852$ \\
\hline
\end{tabular}

\section{b. Inmates' Anxiety Data Variable}

Variable of new inmates' anxiety level is the independent variables serving as the predictors of effects of REB counseling using patronage technique. Based on the predetermined criteria, the new inmates' anxiety level of 31.579 (Table 3 with $\mathrm{N}=240$ ) is categorized as high anxiety.

The $\bar{X}$ coefficients shown in Table 3 can be interpreted following the norms presented in Table 2. Table 2 shows the obtained inmates' anxiety level $=31.579>29.902$, classified as a high category. Meanwhile, Table 1 shows the anxiety level of EG-A1 $=38.292$, categorized as high anxiety because $>29.902$ and $<39.852$. Similarly, the coefficient score of the CG-B1, CG-B2, EG-C2, and CG-D2 also represent high anxiety levels, while the EG-A2 attain 13.575, classified as normal anxiety. The EG-A2 group has received REB therapy through patronage counseling. Thus, the treatment reduces the inmates' anxiety, which is initially high, into normal, by 24.717 points. 
Table 3. Description of WBP Anxiety Variables

\begin{tabular}{|c|c|c|c|c|c|c|c|c|c|c|c|}
\hline & \multirow{2}{*}{ N Stat } & \multirow{2}{*}{$\begin{array}{c}\text { Range } \\
\text { Stat }\end{array}$} & \multirow{2}{*}{$\begin{array}{l}\text { Min } \\
\text { Stat }\end{array}$} & \multirow{2}{*}{$\begin{array}{l}\text { Max } \\
\text { Stat }\end{array}$} & \multirow{2}{*}{ Sum Stat } & \multirow{2}{*}{$\begin{array}{c}\text { Mean } \\
\text { Stat }\end{array}$} & \multirow{2}{*}{$\begin{array}{c}\text { StdDev } \\
\text { Stat }\end{array}$} & \multicolumn{2}{|c|}{ Skew } & \multicolumn{2}{|c|}{ Kurt } \\
\hline & & & & & & & & Stat & StdEr & Stat & StdEr \\
\hline Level Anxieties & 240 & 33.51 & 10.42 & 43.93 & 7579.29 & 31.579 & 9.471 & -1.023 & 0.157 & -0.344 & 0.313 \\
\hline
\end{tabular}

On the other hand, the anxiety level of CG-B1 is 37.975, slightly different (by 0.03 points) from EG-A1. Both of them were observed before attending therapy. However, in CG-B2, which has not been given REB therapy through patronage counseling, the final anxiety level is 37.13 , showing 0.317 points decrease. In addition, EG-C2, which has not been provided with pretest but has received REB therapy through patronage counseling, obtain an anxiety level of 25.550, presenting a relatively slight difference from EG-A1, CG-B1, and CG-B2. Simultaneously, it shows a significant difference from CG-D2 (36,960), which has not received REB therapy through patronage counseling. The significance of EG-A2 anxiety level and its difference from CG-D2 are analyzed through hypothesis testing, along with the effects of REB therapy through patronage counseling on decreasing inmates' anxiety levels. This experimental study involved 160 research subjects producing 240 data from 6 observation groups with 40 cases on each group. The 40 cases for each group hinders the use of non-parametric analysis since the number of cases is too large. Thus, the study used Norton's consideration and concluded that the two observation groups tend to be normal Ramsey, (2007) because the difference in the samples being compared is 0 [50]. Besides, the comparison test results of the samples' number, as carried out by Razali \& Yap (2011), is also appropriate [51].

The $\mathrm{H}_{0}$ states that the anxiety level of the inmates' group (A1) before and after (A2) attending the REB therapy with patronage has no differences. Table 3 shows the coefficient of new inmates' anxiety before the REB therapy with the patronage counseling $(\mathrm{EG}-\mathrm{A} 1)=38.292$, while after being given therapy, the coefficient is 24.717 , decreased by 13.575. The significant difference in anxiety levels before and after therapy was tested, resulting in obtained coefficient $t=44.796$ and Sign $=0.000<0.05$. Thus, the first H0 is rejected (H0: A1 < A2). Besides, the result also shows a significant difference between the new inmates' anxiety levels before (A1) and after (A2) receiving REB therapy with patronage counseling. The therapy is confirmed to reduce the new inmates' anxiety level substantially. The $\mathrm{H}_{0}$ in the second hypothesis states that the new inmates' anxiety level (A1), which has not received REB therapy with patronage counseling, and the anxiety level new inmates' group (B1), which have not and do not receive therapy REB with this technique is the same $\left(\mathrm{H}_{0}::_{\mathrm{A} 1}={ }_{\mathrm{B} 1}\right)$. The statistical analysis results in the coefficient $\mathrm{t}=0.046$ with a significance of $0.964>0.05$ (observation Group column EG-A1 and CG-B1). Therefore, the $\mathrm{H}_{0}\left(\mu_{\mathrm{A} 1}=_{\mathrm{B} 1}\right)$ is accepted. It represents that the inmates' group who has not received REB therapy with the patronage counseling technique has the same high anxiety as the group that does not receive the therapy.

This hypothesis examines the anxiety level difference between EG-A2 that has been given REB therapy with patronage technique and the CG-B1 group that was not given any treatment (therapy). The tested hypothesis states there is no anxiety level difference between the new inmates' group (A2) who have received REB therapy with patronage counseling techniques and group (B1) who have not received the therapy $\left(\mathrm{H}_{1}: \mu_{\mathrm{A} 2}={ }_{\mathrm{B} 1}\right)$. This hypothesis is rejected, because the obtained coefficient $t=-49.26$ with a significance $=0.000<=0.05$ (Table 4 ). It signifies that the anxiety level of the new inmates (A2) who have been given REB therapy with patronage counseling is lower than the CG-B1 group, which was not given any treatment (therapy), with a ratio of 13.575: 37.975 and 24.400 points of difference, classified as significant.

Table 2. Combined Summary of t-Test Results

\begin{tabular}{|c|c|c|c|c|c|c|c|c|}
\hline \multirow{2}{*}{\multicolumn{2}{|c|}{ Observation Group }} & \multirow{2}{*}{$\mathbf{n}$} & \multirow{2}{*}{$\bar{X}$} & \multicolumn{2}{|c|}{ Similarity Test Levene Variance } & \multicolumn{3}{|c|}{ T-Test Mean Average } \\
\hline & & & & $\mathbf{F}$ & Sig & $\mathbf{T}$ & df & Sign ( 2 tail) \\
\hline \multirow[t]{6}{*}{ EG-A1 } & & 40 & 38.292 & & & & & \\
\hline & EG-A2 & 40 & 13.575 & 1.257 & 0.266 & 44.796 & 78 & 0000 \\
\hline & CG-B1 & 40 & 37.975 & 1.695 & 0.197 & 0.046 & $\begin{array}{l}7 \\
8\end{array}$ & 0.964 \\
\hline & CG-B2 & 40 & 37.425 & 3.509 & 0.065 & 1.111 & 78 & 0.270 \\
\hline & EG-C2 & 40 & 25.550 & 1.129 & 0.291 & 22.782 & 78 & 0.000 \\
\hline & CG-D2 & 40 & 36.950 & 0.737 & 0.393 & 1.862 & 78 & 0.564 \\
\hline \multirow[t]{5}{*}{ EG-A2 } & & 40 & 13.575 & & & & & \\
\hline & CG-B1 & 40 & 37.975 & 0.064 & 0.801 & -49.260 & 78 & 0.000 \\
\hline & CG-B2 & 40 & 37.425 & 0.581 & 0.448 & -51.579 & 78 & 0.000 \\
\hline & EG-C2 & 40 & 25.550 & 0.005 & 0.946 & -24.210 & 78 & 0.000 \\
\hline & CG-D2 & 40 & 36.950 & 0.041 & 0.840 & -45.503 & 78 & 0.000 \\
\hline
\end{tabular}




\begin{tabular}{ccccccccc}
\hline CG-B1 & & 40 & 37.975 & & & & & \\
& CG-B2 & 40 & 37.425 & 0.194 & 0.661 & 1.184 & 78 & 0.240 \\
& EG-C2 & 40 & 25.550 & 0.101 & 0.752 & 25.015 & 78 & 0.000 \\
& CG-D2 & 40 & 36.950 & 0.182 & 0.671 & 1.988 & 78 & 0.050 \\
CG-B2 & & 40 & 37.425 & & & & & 0.000 \\
& EG-C2 & 40 & 25.550 & 0.703 & 0.404 & 25.600 & 78 & 0.330 \\
& CG-D2 & 40 & 36.950 & 0.819 & 0.368 & 0.981 & 78 & 0.000 \\
\hline EG-C2 & & 40 & 25.550 & & & & & \\
\hline
\end{tabular}

The next hypothesis reads, there is no difference between the anxiety levels of the inmates' group (A2) who have received REB therapy with patronage counseling technique and the group (B2) who have not received REB therapy $\left(\mathrm{H}_{1}:_{\mathrm{A} 2}{ }_{\mathrm{B} 2}\right)$. The EG-A2 is observed after the group attended REB therapy with patronage counseling technique and was compared with CG-B2, which was observed during pre- and post-therapy even though no therapy was provided. The obtained results are $t=-51.579$ with a significance of $0.000<=00.5$ (Table 4). Consequently, the null hypothesis is rejected. It indicates a significant difference in anxiety level between the EG-A2 and the CG-B2. The average anxiety level of EG-A2 is lower than the anxiety level of CG-B2, with a ratio of 13.575: 37.425 .

The hypothesis for the different test between the inmates' anxiety levels in the EG-A2 and EG-C2 state that the inmates' anxiety level in the group (A2) who had received REB therapy with patronage counseling technique is similar with the inmates' group (C2) who also received REB therapy $\left(\mathrm{H}_{0}: \mu_{\mathrm{A} 2}=\mu_{\mathrm{c} 2}\right)$. According to the data presented in Table 4 , the obtained coefficient is $\mathrm{t}=-24.210$ with a significance of $0.00<0.05$ so that $\mathrm{H}_{0}$ is rejected. Table 4 also shows that the anxiety level of the EG-A2 $=13,575$ is lower compared to the anxiety level of the EG-C2 WBP $=25,550$. The difference between those two groups is 11.975 points, categorized as significant. It signifies that even though both groups have attended the REB therapy with patronage counseling, the EG-A2 which has been tested twice obtained the more normal anxiety level.

The last hypothesis state that there is no inmates' anxiety level difference between group (A2) who has received REB therapy with patronage counseling technique and the group (D2) who have not attended REB therapy $\left(\mathrm{H}_{0}: \mu_{\mathrm{A} 2}=\right.$ $\left.\mu_{\mathrm{D} 2}\right)$. The data presented in Table 4 suggest that the coefficient $\mathrm{t}=-45.503$ with a significance $(2$ tails $)=0.000<0.05$. Thus, this study concludes that the proposed hypothesis is rejected. In other words, the inmates' anxiety level in the group (A2) who had received REB therapy with the patronage counseling technique is confirmed to be different from the group (D2) who had not received REB therapy. The average inmates' anxiety level (A2) is lower (13.575) than the group (D2) (36.950).

A number of studies have reported that REBT theory carries positive and significant effects in overcoming mental health issues, such as anxiety, depression, and so forth [11-18, 52-56]. However, the REBT treatment with patronage technique has not been investigated and implemented in a correctional institution. Patronage technique was used in the counseling treatment for the inmates who experienced anxiety so that the counseling was carried out using the patronclient platform.

Table 3. Outline of Patronage Technique

\begin{tabular}{ccc}
\hline Item & Counselor & Client/Counselee \\
\hline Standard & Formality & Repression, Imperative \\
Principle & Safe, Orderly, Discipline & Obedience, Discipline \\
Status & Officer, Superior & Inmates, Inferiority \\
Purpose & Reintegration, awareness & No self-aware, Finding Activities \\
Target & Awareness, Transformation & Access, Privilege, Get Help \\
Interaction & Instruction & Ready \\
Transaction & Usefulness & Diligent and Discipline \\
Communication & Formal Language & Manner \\
Briefing & Direct & Immediate Preparedness \\
Guidance & Official & Tend not be Understood \\
Authority & Following & No Sense of Belonging, No Self-Defense \\
Influence & Following Main Duties and Functions and Punishment & Determined \\
Action & Dominance & High Alertness \\
Time & As Soon As Possible & - \\
- & Flexible & - \\
\hline
\end{tabular}




\section{4-2- Discussion}

The results of data analysis indicate a significant difference in new inmates' anxiety levels before and after receiving the REBT counseling with patronage techniques. Some of the inmates' who attended the admission orientation (AO) program and did not receive the Reb therapy with patronage counseling presents higher anxiety levels than the inmates' who have received the therapy.

The inmates in the experiment group (EG) (A1) obtained high anxiety levels $(\bar{X}=38.292)$ that have no significant difference from the control group. Their anxiety level is also similar to the other control group (CG) (D2) that has received no REB therapy but was tested during the AO program. However, compared to their initial anxiety level, the inmates in the EG group who have attended the REB therapy attain significantly different anxiety levels after the therapy (EG-A2, $(\bar{X}=13,575)$. Similarly, the EG-A2 also presents substantially different anxiety levels compared to the other groups who have received the same REB therapy but did not undergo the pre-test (EG-C2, $(\bar{X}=25,550)$. Simultaneously, the EG-C2 also attain significantly different anxiety levels compared to the inmates' anxiety levels in other control groups (B1, B2, and D2).

The control group (CG) serves as the control toward the experiment group treated with REB therapy. Besides, the experiment group has also been tested twice, in the pre-test and the post-test. The results of the experiment group's pre-test and post-test show substantial differences. Therefore, the REB therapy using the patronage technique is proven to be efficient in reducing the new inmates' anxiety level. Initially, the inmates' pre-test score in the CG-B1 ( $\bar{X}=$ $37,975)$ has no significant difference from the pre-test results of CG-A1 $(\bar{X}=38,292)$. However, those results present a substantial difference with CG-A2 $(\bar{X}=13,575)$ that has received REB therapy with patronage counseling. Therefore, the REB counseling carries effect in reducing the new inmates' anxiety level.

In addition, the post-test results on the new inmates' anxiety level in the EG-C2 after the REB therapy with patronage counseling $(\bar{X}=25.550)$ also show significant distinction with the inmates in CG-D2 $(\bar{X}=36.950)$ that have attended the AO program but received no REB therapy. Interestingly, the results of final screening $(\bar{X}=13.575)$ after the REB therapy on the inmates' anxiety level in EG-A2 present a great difference with the results of final screening on the EG-C2 who have not been given pre-test $(\bar{X}=25,550)$. Even with the same REB therapy, the inmates in EG-A2 have lower anxiety levels than the inmates in EG-C2 since they have been provided with the pre-test. Therefore, the REB therapy efficiently transforms the high anxiety level into a normal anxiety level.

Additionally, the anxiety level of the inmates in EG-C2 is classified as low, while the inmates' anxiety level in CGD2 that has not received REB therapy with patronage counseling has a high anxiety level. Therefore, both CG-C2 and CGD2 r=that received no pre-test still present significantly different results. However, the most maximum anxiety reduction is observed in the inmates in the EG-A2. Therefore, this study presumed the occurrence of maturity factor in the inmates in EC-A2, resulted from their experience in filling the same instrument. Consequently, this study also concludes that another group of CG is required to serve as the placebo that receives pseudo-REB therapy.

Substantially, REB therapy has a significant impact on psychological issues related to irrational and emotional behavior (Ellis, 1974) [57].Therefore, this therapy accentuates how humans think, feel, and act simultaneously. Humans rarely feel without thinking, since their feelings originate from their perspective on a specific aspect. Once they feel, they will think and act simultaneously. Therefore, humans are not only mere biological creatures with instincts. This statement is against the existential perspective on the human tendency to self-actualize themselves by following their biological nature and their instincts [58]. Pitoewas (2018) states that the social environment becomes one of the factors that has great effects on an individual or a group of individuals acting or changing their behavior and attitude [59]. Mitchell and Krumboltz (1996) also described four factors that affect human career-related decision making, namely genetical, environmental, skills, and learning, in facing a problem [60].

The results of this study are linear with previous studies that support the theory of Ellis, stating that the general effects of REB therapy carry substantial positive effects in solving psychological issues such as anxiety, depression, somatization, hostility, paranoid, ideation, psychotic, and so forth [11-18]. Similarly, the REBT therapy intervention also decreases anxiety and irrational beliefs [19]. These results on the use of REB therapy are also in accordance with the study that reports the efficiency of REB therapy in decreasing irrational beliefs, anxiety, and drug addiction caused by anxiety [53, 54, 61-63]. Similar to the efficiency of REB therapy in reducing psychological issues, some studies have also recorded the success of cognitive behavior therapy in decreasing psychological disorders [64-67].

\section{5- Conclusion}

Mental health disorders can be caused by limited freedom of movement (as experienced by new inmates), pressure, obstacles in determining appropriate behavior, and decreased adaptability due to crowded and unhealthy environments. One of the mental health disorders encountered by new inmates is high anxiety levels, causing them to think irrationally, resulting in the emergence of riots, fights between inmates, resistance toward the prison officer, escapes, and suicide cases in Indonesia's correctional institution. To minimize these symptoms, Rational Emotive Behavior 
Therapy (REBT) with patronage techniques is provided. This counseling model emphasizes the connection between feelings, behavior, and thoughts in order for prisoners to gradually adapt and change their illogical and irrational ways of thinking into something logical and rational. Because inmate counseling differs from general counseling, REBT is implemented using patronage counseling techniques. This technique was selected due to the unequal position of the supervising officers in the Correctional Institution and the inmates, considering their responsibilities and obligations, along with the giving and understanding the meaning of life, gratitude, and happiness for the new inmates. The results of this study show a decrease in new inmates' anxiety levels after receiving REBT counseling therapy with patronage technique.

\section{6- Declarations}

\section{6-1- Author Contributions}

Conceptualization, F.J.; methodology, F.J. and F.H.; software, F.H., M.R. and A.J.S.; validation, F.J., F.H., and A.J.S.; formal analysis, F.J. and M.R.; investigation, F.J.; resources, F.J., F.H., and M.R.; data curation, F.J. and A.J.S.; writing - original draft preparation, F.J.; writing - review and editing, F.H.; visualization, F.J., and A.J.S.; supervision, F.H., M.R. and A.J.S.; project administration, F.J. All authors have read and agreed to the published version of the manuscript.

\section{6-2- Data Availability Statement}

The data presented in this study are available in article.

\section{6-3- Funding}

The authors received no financial support for the research, authorship, and/or publication of this article.

\section{6-4- Acknowledgements}

We would like to thank Tim Percepatan Publikasi, Universitas Negeri (Indonesia) for their guidance in writing this paper.

\section{6-5- Institutional Review Board Statement}

Not applicable.

\section{6-6- Informed Consent Statement}

Informed consent was obtained for all subjects involved in the study.

\section{6-7- Conflicts of Interest}

The authors declare that there is no conflict of interests regarding the publication of this manuscript. In addition, the ethical issues, including plagiarism, informed consent, misconduct, data fabrication and/or falsification, double publication and/or submission, and redundancies have been completely observed by the authors.

\section{7- References}

[1] Paas, F. G. W. C., \& Van Merriënboer, J. J. G. (1994). Instructional control of cognitive load in the training of complex cognitive tasks. Educational Psychology Review, 6(4), 351-371. doi:10.1007/BF02213420.

[2] Acerbi, A., Jacquet, P. O., \& Tennie, C. (2012). Behavioral constraints and the evolution of faithful social learning. Current Zoology, 58(2), 307-318. doi:10.1093/czoolo/58.2.307.

[3] Edwards, J. (2018). Harry helson's adaptation-level theory, happiness treadmills, and behavioral economics. Journal of the History of Economic Thought, 40(1), 1-22. doi:10.1017/S1053837216001140.

[4] Shahsavarani, A. M., Abadi, E. A., M., \& Kalkhoran, M. H. (2015). Stress: Facts and Theories through Literature Review. International Journal of Medical Reviews, 2(2), 230-241.

[5] Abudi, R., Mokodompis, Y., \& Magulili, A. N. (2020). Stigma Terhadap Orang Positif Covid-19. Jambura Journal of Health Sciences and Research, 2(2), 77-84. doi:10.35971/jjhsr.v2i2.6012.

[6] SDP Publik. (2022). Ditjen PAS-SDP Publik. Available online: http://sdppublik.ditjenpas.go.id/ (accessed on January 2022).

[7] Sullivan, E. A., Kendall, S., Chang, S., Baldry, E., Zeki, R., Gilles, M., Wilson, M., Butler, T., Levy, M., Wayland, S., Cullen, P., Jones, J., \& Sherwood, J. (2019). Aboriginal mothers in prison in Australia: a study of social, emotional and physical wellbeing. Australian and New Zealand Journal of Public Health, 43(3), 241-247. doi:10.1111/1753-6405.12892. 
[8] Nevid, J. S., Rathus, S. A., \& Greene, B. (2003). Abnormal Psychology in a changing world. International Edition (8th ed.). Prentice Hall, New Jersey, United States.

[9] Gunarsa, S. D. (2008). Psikologi perkembangan anak dan remaja. BPK Gunung Mulia, Jakarta, Indonesia.

[10] Lake, E. A., \& Arkin, R. M. (1985). Reactions to Objective and Subjective Interpersonal Evaluation: The Influence of Social Anxiety. Journal of Social and Clinical Psychology, 3(2), 143-160. doi:10.1521/jscp.1985.3.2.143.

[11] Gonzalez, J. E., Ron Nelson, J., Gutkin, T. B., Saunders, A., Galloway, A., \& Shwery, C. S. (2004). Rational emotive therapy with children and adolescents: A meta-analysis. Journal of Emotional and Behavioral Disorders, 12(4), $222-235$. doi:10.1177/10634266040120040301.

[12] Vaida, S., Kállay, É., \& Opre, A. (2008). Counseling in schools. A rational emotive behavior therapy (REBT) based intervention-A pilot study. Cognition, Brain, Behavior, 12(1), 57.

[13] Kumar, G. V. (2009). Impact of rational-emotive behaviour therapy (REBT) on adolescents with conduct disorder (CD). Journal of the Indian Academy of Applied Psychology, 35(Special Issue), 103-111.

[14] Siburian, E.K., \& Kaloeti, D.V.S. (2010). Effect of Rational Emotive Behavioral Therapy (Rebt) in Reducing Anxiety Facing the Future in Drug Abusers in Rehabilitation Institutions. Psychology Journal (Jurnal Psikologi), 7(1), 40-49. doi:10.14710/jpu.7.1.40-49.

[15] Spörrle, M., Strobel, M., \& Tumasjan, A. (2010). On the incremental validity of irrational beliefs to predict subjective wellbeing while controlling for personality factors. Psicothema, 22(4), 543-548.

[16] Turner, M., \& Barker, J. B. (2013). Examining the Efficacy of Rational-Emotive Behavior Therapy (REBT) on Irrational Beliefs and Anxiety in Elite Youth Cricketers. Journal of Applied Sport Psychology, 25(1), $131-147$. doi:10.1080/10413200.2011.574311.

[17] Turner, M. J., Barker, J. B., \& Slater, M. J. (2014). The season-long effects of rational emotive behavior therapy on the irrational beliefs of professional academy soccer athletes. International Journal of Sport Psychology, 45(5), 429-451. doi:10.7352/IJSP.2014.45.429.

[18] Yunita, M. M. (2017). Application of Rational Emotive Behavior Therapy (Rebt) to Improve Psychological Well-Being in Grandmal Epilepsy Patients. Psybernetics (Psibernetika), 9(2), 136-145. doi:10.30813/psibernetika.v9i2.470.

[19] Mousavi Nik, M., Assari, A., Khaneh Keshi, A., \& Reza Eshaghi Farahmand, S. (2014). The Second International Anxiety Congress Effect of Rational Emotive Behavior Therapy (REBT) on Anxiety and Irrational Beliefs among Infertile Women. The Neuroscience Journal of Shefaye Khatam, 2(3), 56-56.

[20] Scott, J. C. (1994). Peasant Economic Morality: Upheaval and Subsistence in Southeast Asia. Basari H. Penerjemah. LP3ES. Terjemahan dari: The Moral Economy of Peasant. Rebelion and Subsistence in Southeast Asia. Jakarta, Indonesia.

[21] Scott, J. C. (1972). Patron-Client Politics and Political Change in Southeast Asia. American Political Science Review, 66(1), 91-113. doi:10.2307/1959280.

[22] American Psychiatric Association. (2013). Diagnostic and statistical manual of mental disorders: DSM-5 (Vol. 5). Washington, DC, United States.

[23] Kaplan, C. A., Thompson, A. E., \& Searson, S. M. (1995). Cognitive behaviour therapy in children and adolescents. Archives of Disease in Childhood, 73(5), 472-475. doi:10.1136/adc.73.5.472.

[24] Seligman, M. E. P., Walker, E. F. \& Rosenhan, D. L. (2001). Abnormal Psychology. (4th ed.). W.W. Norton \& Company, Inc. New York, United States.

[25] Hall, C.S. (1954). A primer of Freudian Psychology. Pickle Partners Publishing, Auckland, New Zealand.

[26] Cahyani, H., Asikin, M., \& Hengky, H. K. (2020). Factors that influence mental health problems in drug convicts at the Class IIb Sidrap detention center. Scientific Journal of Humans and Health (Jurnal IlmiahManusia Dan Kesehatan), 1(1), 43-52.

[27] Anggraini, D., Hadiati, T., \& Sarjana, W. (2019). Differences in stress levels and the level of resilience of newly admitted inmates with convicts who will soon be released (Study on prisoners at the Class II Penitentiary for Women in Semarang. Diponegoro Medical Journal, 8(1), 148-160. doi:10.14710/dmj.v8i1.23308.

[28] Feoh, F. T. (2020). Studi fenomenologi: Stressnarapidana perempuan pelaku humantrafficking. Jurnal Ilmiah Nursing, 11(3), 7-16. doi:10.36089/nu.v11i3.214.

[29] Wolpe, J. (1968). Psychotherapy by reciprocal inhibition. In Conditional reflex: a Pavlovian journal of research \& therapy (Vol. 3, Issue 4). Stanford University Press. doi:10.1007/BF03000093.

[30] Skinner, B. F. (1973). Beyond Freedom and Dignity 1971. Bantam, Vintage Book, Pennsylvania, United States. 
[31] Rieg, S. A., Paquette, K. R., \& Chen, Y. (2007). Coping With Stress: an Investigation of Novice Teachers' Stressors I. Education, 128(2), 211-226.

[32] Silverman, S., \& DiGiuseppe, R. (2001). Cognitive-behavioral constructs and children's behavioral and emotional problems. Journal of rational-emotive and cognitive-behavior therapy, 19(2), 119-134. doi:10.1023/A:1011183506003.

[33] Aydin, A., Tekinsav-Sütçü, S., \& Sorias, O. (2010). Evaluation of the effectiveness of a cognitive-behavioral therapy program for alleviating the symptoms of social anxiety in adolescents. Turk Psikiyatri Dergisi, 21(1), 1-11.

[34] Narayan, A. J., Nerenberg, L. S., Kalstabakken, A. W., Labella, M. H., Monn, A. R., \& Masten, A. S. (2017). Intergenerational continuity of adverse childhood experiences in homeless families: Unpacking exposure to maltreatment versus family dysfunction. American Journal of Orthopsychiatry, 87(1), 3-14. doi:10.1037/ort0000133.

[35] Guze, Samuel B. (1994). "Diagnostic and Statistical Manual of Mental Disorders, 4th Ed. (DSM-IV)." American Journal of Psychiatry 152(8), 1228-1228. doi:10.1176/ajp.152.8.1228.

[36] Hunt, A. (1999). Anxiety and social explanation: Some anxieties about anxiety. Journal of Social History, 32(3), 509-528. doi:10.1353/jsh/32.3.509.

[37] Psychology Today. (2022). Rational Emotive Behavior Therapy. Available online: https://www.psychologytoday.com/us/ therapy-types/rational-emotive-behavior-therapy (accessed on January 2022).

[38] Ellis, A. (1996). Reason and Emotion in Psychotherapy: A Comprehen-Sive Method of Treating Human Distrubances. Citadel Publishing LLC, New York, United States.

[39] Ellis, A. (1995). Changing rational-emotive therapy (RET) to rational emotive behavior therapy (REBT). Journal of RationalEmotive \& Cognitive-Behavior Therapy, 13(2), 85-89. doi:10.1007/BF02354453.

[40] Ellis, A. (1958) Rational Psychotherapy, Journal of General Psychology, 59:1, 35-49, doi: 10.1080/00221309.1958.9710170.

[41] Ellis, D. J. (2017). Rational Emotive Behavior Therapy and Individual Psychology. The Journal of Individual Psychology, 73(4), 272-282. doi:10.1353/jip.2017.0023.

[42] Ellis, A. (2001). Feeling Better, Getting Better, Staying Better. Impact Publishers, Oakland, United States.

[43] Ellis, A. (1993). The Advantages and Disadvantages of Self-Help Therapy Materials. Professional Psychology: Research and Practice, 24(3), 335-339. doi:10.1037/0735-7028.24.3.335.

[44] Alhadi, S., Purwadi, P., Muyana, S., Saputra, W. N. E., \& Supriyanto, A. (2018). SMP Student Aggressiveness in Yogyakarta. Counseling Focus Journal (Jurnal Fokus Konseling), 4(1), 93. doi:10.26638/jfk.507.2099.

[45] Teguh, M., Maria, A., Gulo, W. M. E. F., \& Hartini, S. (2020). Aggressive Behavior Judging From Work Stress on Employees. Psychostudia: Journal of Psychology, 9(2), 127. doi:10.30872/psikostudia.v9i2.3909.

[46] George, R. L., \& Cristiani, T. S. (1990). Counseling TheSory and Practice (3rd ed.). Prentice Hall, New Jersey, United States.

[47] Corey, G. (2011). Theory and practice of counseling and psychotherapy. Cengage learning. California State University, Fullerton, California, United States.

[48] Hanurawan, F. (2015). Ilmu Psikologi Untuk Pemecahan Masalah-Masalah Kemanusiaan. Pidato Pengukuhan Guru Besar dalam Bidang Ilmu Psikologi pada Fakultas Pendidikan Psikologi disampaikan pada Sidang Terbuka Senat Universitas Negeri Malang, Indonesia.

[49] Usman, S. (2004). Pembangunan dan Pemberdayaan Masyarakat. Yogyakarta: Pustaka Pelajar, Yogyakarta, Indonesia.

[50] Ramsey, P.H. (2007). Encyclopedia of Measurement and Statistics. Edited by Salkind, N.J \& Rasmussen, K. Thousand Oaks: Sage Publication. doi:10.4135/9781412952644.

[51] Razali, N. M., \& Wah, Y. B. (2011). Power comparisons of shapiro-wilk, kolmogorov-smirnov, lilliefors and anderson-darling tests. Journal of statistical modeling and analytics, 2(1), 21-33.

[52] Gharavi, M. M., Kashani, H., Lotfi, M., \& Borhani, M. (2015). Comparison of depression, anxiety, general mental health and self- esteem among prisoners in consultancy and ordinary wings. Fundamentals of Mental Health, 17(12), 52-57.

[53] Stevani, H., Mudjiran, M., \& Iswari, M. (2016). Effectiveness of Group Guidance Services with Rational Emotive Behavior Therapy Approach to Overcome Student Anxiety. Counselor (Konselor), 5(1), 15. doi:10.24036/02016516479-0-00.

[54] Thahir, A., \& Rizkiyani, D. (2017). The Effect of Rational Emotive Behavioral Therapy (REBT) Counseling in Reducing Anxiety for Class VIII Students at Gajah Mada Junior High School Bandar Lampung. Counselees: Guidance and Counseling Journal (Konseli: Jurnal Bimbingan Dan Konseling), 3(2), 197-206. doi:10.24042/kons.v3i2.560.

[55] Sari, C. (2018). The Effectiveness of Group Counselling Using a Rational Emotive Behavior Therapy (Rebt) Approach to Reduce Anxiety for Middle School Students at Masjid Syuhadak Yogyakarta. G-Couns: Guidance and Counselling Journal (G-Couns: Jurnal Bimbingan dan Konseling), 3(1). doi:10.31316/g.couns.v3i1.91. 
[56] Febrianto, B., \& Ambarini, T. K. (2019). The effectiveness of reality group counseling to reduce anxiety in correctional clients. Scientific Journal of Applied Psychology (Jurnal Ilmiah Psikologi Terapan), 7(1), 132. doi:10.22219/jipt.v7i1.7838.

[57] Ellis, A. (1957). Rational-Emotive Theory: Albert Ellis. In A. Burton (Ed.), Operational Theories of Personality. Brunner/Mazel. American Psychological Association, Washington DC, United States.

[58] Corey, G. (2013). Theory and Practice of Counseling \& Psychotherapy. Translate E. Victor. Bandung. Refika Aditama, Bandung, Indonesia.

[59] Pitoewas, B. (2018). The Influence of Social Environment and Adolescent Attitudes towards Changes in Values. Journal of Pancasila and Citizenship (Jurnal Pancasila Dan Kewarganegaraan), 3(1), 8-18. doi:10.24269/jpk.v3.n1.2018.pp8-18.

[60] Mitchell, L.K., \& Krumboltz J.D. (1996). Krumboltz's learning theory of career choice and counseling', Career choice and development, Jossey-Bass San Francisco, California, United States.

[61] Rovira Aler, C., Fuentes Leiva, M. I., Fernández Bonet, X., Almeda Ortega, J., Cunillera Puertolas, O., \& Edo Izquierdo, S. (2016). Effectiveness of Rational Emotive Behaviour Therapy in Clinical Social Work: Impact on Frequency of Visits and Use of Psychopharmacological Treatment. International Journal of Integrated Care, 16(6), 6. doi:10.5334/ijic.2949. doi:10.5334/ijic.2949.

[62] Wood, A. G., Barker, J. B., Turner, M. J., \& Sheffield, D. (2018). Examining the effects of rational emotive behavior therapy on performance outcomes in elite paralympic athletes. Scandinavian Journal of Medicine and Science in Sports, 28(1), 329339. doi:10.1111/sms.12926.

[63] Mangayarkarasi, K., \& Kannaiah Sellakumar, G. (2017). Efficacy of Rational Emotive Therapy in the Management of Depression in Hiv Infected Women. International Journal of Education and Psychology in the Community IJEPC, 2017(2), 41-64. Available online: https://www.ceeol.com/search/article-detail?id=556785 (accessed on January 2021).

[64] Oltean, H. R., Hyland, P., Vallières, F., \& David, D. O. (2017). An Empirical Assessment of REBT Models of Psychopathology and Psychological Health in the Prediction of Anxiety and Depression Symptoms. In Behavioural and cognitive psychotherapy 45(6), 600-615. doi:10.1017/S1352465817000133.

[65] Purnamaningsih, E. H., \& Utami, M. S. (1998). Effectiveness of Cognitive Behavioral Therapy to Reduce Public Speaking Anxiety. Psychology Journal (Jurnal Psikologi), 25(1), 65-76. doi:10.22146/jpsi.9853.

[66] Deacon, B. J., \& Abramowitz, J. S. (2004). Cognitive and Behavioral Treatments for Anxiety Disorders: A Review of Metaanalytic Findings. Journal of Clinical Psychology, 60(4), 429-441. doi:10.1002/jclp.10255.

[67] Prasetyaningrum, S., Fasikhah, S. S., and Karmiyati, D. (2012). Behavioral Cognitive Therapy to Reduce Anxiety Levels in Post-Stroke Patients. Journal of Psychological Intervention (Jurnal Intervensi Psikologi), 4(1), 82-95. doi:10.20885/intervensipsikologi.vol4.iss1.art7. 